\title{
Prognosis of neutrophil-to-lymphocyte ratio in clinical early-stage tongue (cTI/T2N0) cancer
}

This article was published in the following Dove Press journal:

OncoTargets and Therapy

4 August 2017

Number of times this article has been viewed

\author{
Ching-Nung Wu' \\ Hui-Ching Chuang ${ }^{1,2}$ \\ Yu-Tsai Lin ${ }^{1,2}$ \\ Fu-Min Fang 2,3 \\ Shau-Hsuan $\mathrm{Li}^{2,4}$ \\ Chih-Yen Chien ${ }^{1,2}$ \\ 'Department of Otolaryngology, \\ Kaohsiung Chang Gung Memorial \\ Hospital, Chang Gung University \\ College of Medicine, Kaohsiung, \\ Taiwan; ${ }^{2}$ Kaohsiung Chang Gung Head \\ and Neck Oncology Group, Cancer \\ Center, Kaohsiung Chang Gung \\ Memorial Hospital, Kaohsiung, Taiwan; \\ ${ }^{3}$ Department of Radiation Oncology, \\ Kaohsiung Chang Gung Memorial \\ Hospital, Chang Gung University \\ College of Medicine, Kaohsiung, \\ Taiwan; ${ }^{4}$ Department of Hematology- \\ Oncology, Kaohsiung Chang Gung \\ Memorial Hospital, Chang Gung \\ University College of Medicine, \\ Kaohsiung, Taiwan
}

Background: Inflammation plays a role in the development of cancer. This study aims to analyze the prognostic value of the neutrophil-to-lymphocyte ratio (NLR) and other clinicopathological determinants in early-stage (cT1/T2N0) tongue cancer.

Materials and methods: A total of 262 patients were selected from our institute's cancer database between 2004 and 2011. Optimal cutoff value of NLR and lymph node density (LND) were determined statistically using receiver operating characteristic curve analysis for survival prediction. The 5-year overall survival (OS), disease-specific survival (DSS), and disease-free survival (DFS) rates were estimated using the Kaplan-Meier method.

Results: The results showed that, in this cohort, the optimal cutoff value of NLR was 2.95 and for LND, it was 0.031 . Patients with NLR $\geq 2.95$ correlated significantly with positive $\mathrm{N}$ classification $(P=0.011)$, T2 classification $(P=0.007)$, positive perineural invasion $(P<0.001)$, and a tumor thickness of $>5 \mathrm{~mm}(P=0.005)$. The 5-year OS among patients with NLR $<2.95$ was much higher than that in patients with NLR $\geq 2.95(P<0.001)$. Similarly, the 5-year DSS among patients with NLR $<2.95$ was much higher than that in patients with NLR $\geq 2.95$ ( $P=0.002$ ). The 5-year DFS among patients with NLR $<2.95$ was much higher than that in patients with NLR $\geq 2.95(P=0.004)$. The 5-year OS, DSS, and DFS were significantly reduced among patients with LND $>0.031$ compared to those with LND $<0.031$, respectively. In multivariate analysis, NLR, LND, and tumor thickness were independent prognostic factors for OS.

Conclusion: Pretreatment NLR $\geq 2.95$ is significantly correlated with a larger tumor, positive neck lymph node metastasis, and positive perineural invasion. Importantly, it indicates reduced survival rate. Therefore, if the NLR $\geq 2.95$ in early-stage (cT1/T2N0) tongue cancer is noted preoperatively, it reveals more invasive tumor behavior clinically. Then, aggressive treatments, including elective neck dissection, become necessary.

Keywords: neutrophil-to-lymphocyte ratio, survival, oral cancer, neck lymph node metastasis, perineural invasion

\section{Introduction}

According to data released in 2012 by the International Agency for Research on Cancer, more than 300,000 new oral cancer cases were diagnosed worldwide. ${ }^{39}$ The tongue remains the most common subsite for oral cavity tumors. The American Joint Committee on Cancer (AJCC) system, including preoperative $\mathrm{T}$ classification and $\mathrm{N}$ classification, is the standard tumor-staging system and is widely used internationally. Despite increased early diagnosis, even patients with T1/T2 stage tumors would show treatment failure. Previously, many studies focused on finding the prognostic factors among patients preoperatively, such as tumor thickness, biomarkers, neck nodal status, and lymph node density (LND). ${ }^{1-4}$
Correspondence: Chih-Yen Chien Department of Otolaryngology, Kaohsiung Chang Gung Memorial Hospital, I23 Ta-Pei Road, Niao-Song District, Kaohsiung 833, Taiwan Tel +886 88773 I 7123 ext 2533 Fax +886 88773 I 3855 Email cychien3965@adm.cgmh.org.tw 
Although inflammatory cells are frequently found in tumor biopsies, the relationship between cancer and the immune system has been increasingly recognized over the past 30 years..$^{5,6}$ The neutrophil-to-lymphocyte ratio (NLR) measures the status of systemic inflammation and may be readily calculated from white blood cell counts. The NLR was reported to be an independent prognostic factor for patients with various types of cancer, and a high NLR was associated with adverse outcomes of lung, esophageal, gastric, colorectal, hepatic, and pancreatic cancers. ${ }^{7-12}$ Recent studies have also shown a negative prognostic value of higher NLR among patients with head and neck cancer. ${ }^{13-18}$ However, there are no studies on the prognostic value of NLR in early-stage (cT1/T2N0) tongue cancer. In addition, the need for elective neck dissection for clinical T1/T2N0 oral cancer was debatable in the past, despite possibly increasing survival rate. ${ }^{19}$ Clinically, it would be worthwhile to study this issue because the inflammatory status and immune response may be different between advanced-stage tumors and early-stage tumors. Exploring the relationship between potential neck lymph node metastasis and NLR is also important in clinical practice. This study aims to identify the clinical significance of NLR and other clinicopathological variables in patients with early-stage (cT1/T2N0) tongue cancer.

\section{Materials and methods Patients}

Between January 2004 and December 2011, 262 patients with newly diagnosed cT1/T2N0 tongue squamous cell carcinoma who had undergone surgery as primary treatment at the Department of Otolaryngology, Kaohsiung Chang Gung Memorial Hospital, Taiwan, were enrolled retrospectively in this study from our cancer database. We excluded patients with chronic hepatitis or human immunodeficiency virus and those who had undergone immunotherapy and steroid or interferon treatment within 3 months before surgery. Information about preoperation hematologic parameters was collected. The NLR value was calculated by dividing the neutrophil count by the lymphocyte count. The T classification, $\mathrm{N}$ classification, and TNM stage were classified according to the 2010 AJCC system. The postoperative pathological data included TNM staging, tumor thickness, LND, lymphovascular invasion (LVI), perineural invasion (PNI), or extranodal extension of lymph node (ENE). The LND was calculated by dividing the number of involved lymph nodes of the disease by the total number of lymph nodes removed. The adjuvant therapy with radiation or chemoradiation of tongue cancer was based primarily on the guidelines of the National Comprehensive Cancer Network for oral cancer. Radiation dose was at least 6,000 cGy, and the chemotherapy was cisplatin based for adjuvant therapy. The study was approved by the Medical Ethics and Human Clinical Trial Committees at Chang Gung Memorial Hospital. Patients' consent to review their medical records was not required by these committees at this hospital because the patient data remained anonymous in this study.

\section{Statistical analyses}

The optimal cutoff values of NLR and LND were determined using receiver operating characteristic curve analysis for survival prediction and then Youden's index equation for the specific value. Survival of prognostic factors was estimated using the Kaplan-Meier method, and the log-rank test determined the heterogeneity due to the specific factor. Cox proportional hazards model tested the independence of primary factors with other prognostic factors in multivariate survival modeling. All tests were two sided, and statistical significance was set at 0.05. All statistical analyses were carried out using the Statistical Package of Social Sciences software, version 20.0 (SPSS, Chicago, IL).

\section{Results}

Of the 262 patients, $87 \%$ (228) were male and $13 \%$ (34) were female; the median age of diagnosis for all was 51 years, ranging from 24 to 85 years. The mean follow-up was 67.1 months (from 2 to 137 months); 101 patients (38.5\%) had a tumor thickness of $<5 \mathrm{~mm}$, and the remaining 161 patients $(61.5 \%)$ showed a tumor thickness of $\geq 5 \mathrm{~mm}$. PNI was found in 48 patients $(18.3 \%)$, LVI in 30 patients $(11.5 \%)$, and ENE in 17 patients (6.5\%). The mean NLR was 2.18 (range: 0.6-7.0), and the mean LND was 0.0197 (range: 0-0.546). At the end of the study, there were $57(21.8 \%)$ patients who had died, and of these, 32 (12.2\%) had died of tongue cancer. Local/regional failure occurred in 45 patients (17.2\%). See Table 1 for the detailed baseline clinicopathological features of the 262 subjects and their survival outcomes.

The optimal cutoff value for NLR was 2.95, and that for LND was 0.031 (Figure 1). Patients with NLR $\geq 2.95$ correlated significantly with positive $\mathrm{N}$ classification $(P=0.011)$, T2 classification $(P=0.007)$, positive PNI $(P<0.001)$, and tumor thickness of $>5 \mathrm{~mm}(P=0.005$; Table 2$)$. The 5 -year overall survival (OS) for patients with NLR $<2.95$ was increased significantly compared with patients with NLR $\geq 2.95$ (86\% vs 57.6\%, $P<0.001$; Figure 2 A). Similarly, the 5-year DSS for patients with NLR $<2.95$ was increased significantly compared with patients with NLR 
Table I Clinicopathological characteristics and outcomes of 262 patients who were diagnosed with clinical early-stage tongue cancer (cTI/T2N0)

\begin{tabular}{|c|c|}
\hline Factor & Number (\%) \\
\hline \multicolumn{2}{|l|}{ Gender } \\
\hline Male & $228(87.0)$ \\
\hline Female & $34(13.0)$ \\
\hline \multicolumn{2}{|c|}{ Drinks alcohol } \\
\hline No & $182(69.5)$ \\
\hline Yes & $80(30.5)$ \\
\hline \multicolumn{2}{|c|}{ Betel nut chewing } \\
\hline No & $69(26.3)$ \\
\hline Yes & 193 (73.7) \\
\hline \multicolumn{2}{|l|}{ Smoker } \\
\hline No & $64(24.4)$ \\
\hline Yes & $198(75.6)$ \\
\hline \multicolumn{2}{|c|}{ T classification } \\
\hline TI & $149(56.9)$ \\
\hline $\mathrm{T} 2$ & $113(43.1)$ \\
\hline \multicolumn{2}{|c|}{$\mathrm{N}$ classification } \\
\hline No & 205 (78.2) \\
\hline $\mathrm{N}+$ & $57(21.8)$ \\
\hline \multicolumn{2}{|c|}{ Tumor thickness } \\
\hline$<5 \mathrm{~mm}$ & I0I (38.5) \\
\hline$\geq 5 \mathrm{~mm}$ & 161 (6I.5) \\
\hline \multicolumn{2}{|l|}{ PNI } \\
\hline No & $2 \mid 4(8 \mid .7)$ \\
\hline Yes & $48(18.3)$ \\
\hline \multicolumn{2}{|l|}{ LVI } \\
\hline No & $232(88.5)$ \\
\hline Yes & $30(11.5)$ \\
\hline \multicolumn{2}{|l|}{ ENE } \\
\hline No & $245(93.5)$ \\
\hline Yes & $17(6.5)$ \\
\hline \multicolumn{2}{|l|}{ LND } \\
\hline$<0.031$ & $218(83.2)$ \\
\hline$\geq 0.031$ & $44(16.8)$ \\
\hline \multicolumn{2}{|l|}{ NLR } \\
\hline$<2.95$ & $2 \mid 4(8 \mid .7)$ \\
\hline$\geq 2.95$ & $48(18.3)$ \\
\hline
\end{tabular}

Abbreviations: ENE, extranodal extension; LND, lymph node density; LVI, lymphovascular invasion; NLR, neutrophil-to-lymphocyte ratio; PNI, perineural invasion.

$\geq 2.95$ (90.4\% vs $73.3 \%, P=0.002$; Figure $2 \mathrm{~B})$. Moreover, the 5-year DFS for patients with NLR $<2.95$ was increased significantly compared with patients with NLR $\geq 2.95(85.3 \%$ vs $67.7 \%, P=0.004$; Figure $2 \mathrm{C}$ ).

Regarding the LND, the 5-year OS (54.2\% vs $86.2 \%)$, DSS (60.7\% vs $92.8 \%$ ), and DFS (54.1\% vs $87.8 \%$ ) were also significantly reduced (all $P<0.001$, Figure 3 ) among patients with LND $>0.031$ compared with those with LND $<0.031$. Other pathological factors, such as T2 classification, positive $\mathrm{N}$ classification, tumor thickness of $\geq 5 \mathrm{~mm}$, positive PNI, and positive ENE, were all significant predictors of poor outcome for 5-year OS, DSS, and DFS (Table 3).
Patients who were betel nut chewers showed significantly reduced 5-year OS $(P=0.003)$ and DFS $(P=0.009)$ compared with those without this habit. In addition, patients who were smokers showed significantly reduced 5 -year OS $(P=0.016)$ and DSS $(P=0.035)$ compared with nonsmokers (Table 3$)$.

In multivariate analyses, NLR $\geq 2.95$ was associated with reduced OS in early-stage (cT1/T2N0) tongue cancer (hazard ratio [HR]: 2.29, 95\% CI: 1.32-3.96) and was adjusted by other independent factors, tumor thickness, and LND (Table 4). In the model, LND - another focusing prognostic factor in this study - had an HR of 2.57 (95\% CI: 1.47-4.48) in LND $\geq 0.031$ reference to LND $<0.031$ for reduced OS (Table 4). Both factors, NLR $\geq 2.95$ and LND $\geq 0.031$, were associated with reduced DSS (HR: 2.10, 95\% CI: 1.00-4.40; HR: 5.15, 95\% CI: 2.55-10.42) and DFS (HR: 1.91, 95\% CI: 1.02-3.59; HR: 1.98, 95\% CI: 0.94-4.17) after being adjusted by other factors (Tables 5 and 6). Tumor thickness of $\geq 5 \mathrm{~mm}$, another independent factor in this model, was also related to poor outcome in OS (HR: 3.38, 95\% CI: 1.48-7.72) and DFS (HR: 6.90, 95\% CI: 2.08-22.91).

\section{Discussion}

In the current study of patients with early-stage (cT1/ T2N0) tongue cancer, we observed 5-year DFS, DSS, and OS rates of $82.8 \%, 87.8 \%$, and $78.2 \%$, respectively. Multivariate analysis indicated that OS was determined mainly by tumor thickness, LND, and NLR. In our study, tumor thickness with a cutoff value of $5 \mathrm{~mm}$ appears to be one of the significant prognostic factors related to 5-year OS and 5-year DFS. Many previous studies have shown that tumor thickness is a major predictive factor for neck lymph node metastasis and is correlated with survival or local recurrence. ${ }^{20}$ The tumor thickness is also found to be an independent predictor of the 5-year DSS in tonsillar cancer. ${ }^{21}$ Noninvasive tools for evaluating tumor thickness by $\mathrm{MRI}^{22}$ and ultrasound ${ }^{23}$ have proven to reliably identify patients who are likely to have a worse clinical outcome at the time of diagnosis.

Currently, the presence of neck metastasis and extranodal extension of lymph nodes remain the most significant predictors of prognosis in oral cancer. ${ }^{24,25}$ Recent studies have shown that traditional clinical nodal staging alone may not reliably predict prognosis or direct treatment in patients with primary squamous cell carcinoma of the tongue. ${ }^{26}$ The concept of surgical staging with regard to nodal disease is a critical strategy for a range of malignancies, ${ }^{27}$ taking into account both the extent of surgical clearance and the true nodal disease burden. This forms the basis of LND as an 

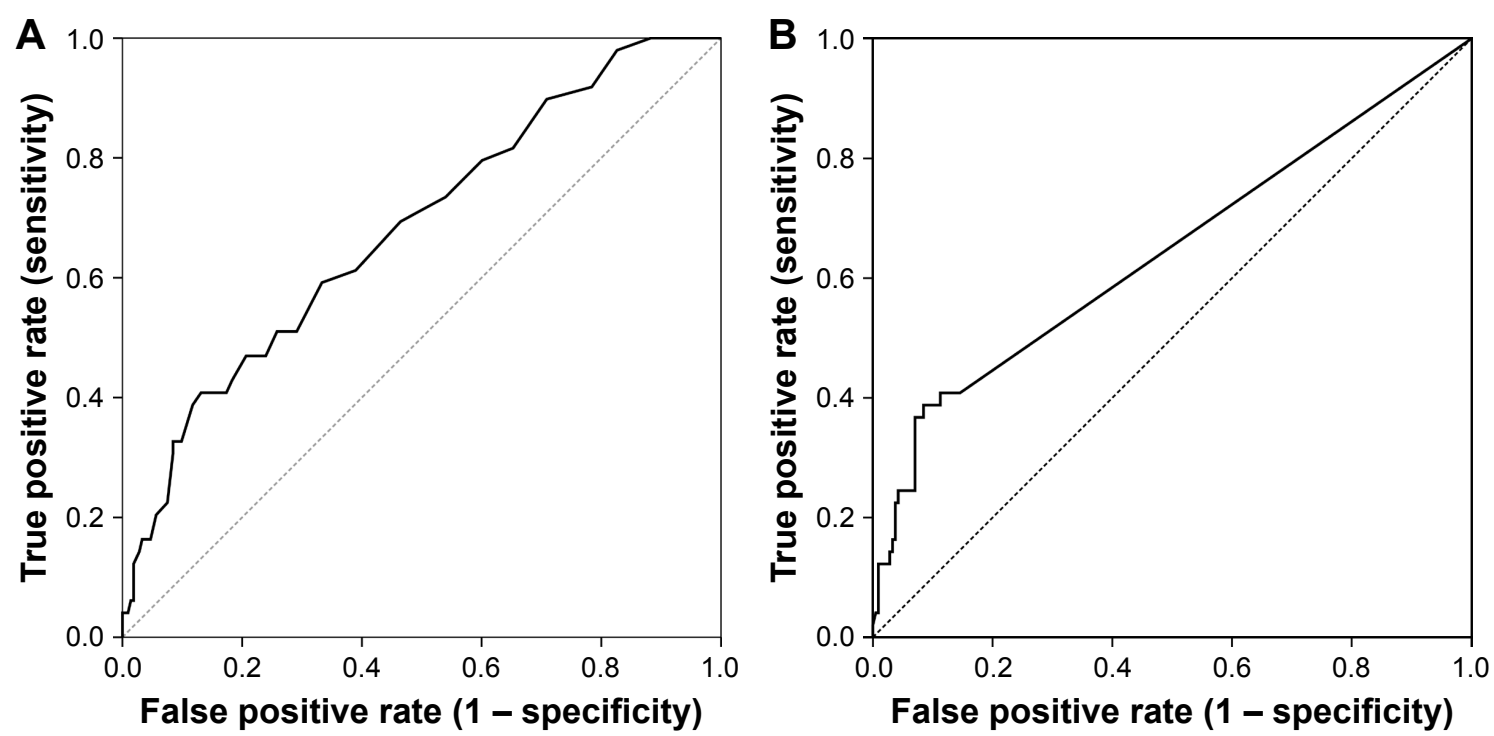

Figure I Receiver operating characteristic curve of (A) NLR and (B) LND for predicting the survival of early-stage tongue cancer patients with AUC equal to 68. I\% and $86.9 \%$, respectively.

Abbreviations: AUC, area under the curve; LND, lymph node density; NLR, neutrophil-to-lymphocyte ratio.

Table 2 Association analysis between NLR and other clinical/ pathological factors

\begin{tabular}{|c|c|c|c|}
\hline \multirow[t]{2}{*}{ Factor } & \multicolumn{2}{|l|}{ NLR } & \multirow[t]{2}{*}{$P$-value } \\
\hline & $<2.95$ & $\geq 2.95$ & \\
\hline Gender & & & 0.913 \\
\hline Male & 186 & 42 & \\
\hline Female & 28 & 6 & \\
\hline Drinks alcohol & & & 0.905 \\
\hline No & 149 & 33 & \\
\hline Yes & 65 & 15 & \\
\hline Betel nut chewing & & & $0.04 I$ \\
\hline No & 62 & 7 & \\
\hline Yes & 152 & 41 & \\
\hline Smoker & & & 0.521 \\
\hline No & 54 & 10 & \\
\hline Yes & 160 & 38 & \\
\hline T classification & & & 0.007 \\
\hline TI & 130 & 19 & \\
\hline $\mathrm{T} 2$ & 84 & 29 & \\
\hline $\mathrm{N}$ classification & & & 0.011 \\
\hline No & 174 & 31 & \\
\hline $\mathrm{N}+$ & 40 & 17 & \\
\hline Tumor thickness & & & 0.005 \\
\hline$<5 \mathrm{~mm}$ & 91 & 10 & \\
\hline$\geq 5 \mathrm{~mm}$ & 123 & 38 & \\
\hline PNI & & & $<0.001$ \\
\hline No & 184 & 30 & \\
\hline Yes & 30 & 18 & \\
\hline LVI & & & 0.801 \\
\hline No & 190 & 42 & \\
\hline Yes & 24 & 6 & \\
\hline ENE & & & $0.94 I$ \\
\hline No & 200 & 45 & \\
\hline Yes & 14 & 3 & \\
\hline LND & & & 0.092 \\
\hline$<0.031$ & 182 & 36 & \\
\hline$\geq 0.03 \mathrm{I}$ & 32 & 12 & \\
\hline
\end{tabular}

Abbreviations: ENE, extranodal extension; LND, lymph node density; LVI, lymphovascular invasion; NLR, neutrophil-to-lymphocyte ratio; PNI, perineural invasion. important prognostic factor, as demonstrated by a number of studies in head and neck squamous cell carcinoma (HNSCC) (Table 7). ${ }^{28-35}$ However, no study until now has explored early-stage (cT1/T2N0) tongue cancer, which is frequently found clinically. The clinical impact of LND is different between advanced-stage and early-stage tumors. Our study confirms this data: 0.031 is much lower than those showed in Table 7.

In this study, we are the first to evaluate the value of LND in early-stage tongue cancer. Patients with LND $>0.031$ have significantly reduced OS, DSS, and DFS. This variable still remained significant for multivariate analysis in OS and DSS (Tables 4 and 5). In contrast, the conventional nodal staging system is inferior to LND in predicting OS, DSS, and DFS in current series noted by multivariate analysis.

In recent years, studies investigating the clinical significance of NLR in HNSCC have increased. It is believed that the white blood cell differential in HNSCC tends toward either a myeloid or a lymphoid lineage. The lymphoid preponderance was associated with better disease outcomes based on previous studies. Several studies found that higher NLR predicted reduced disease-specific survival and OS in HNSCC (Table 8). ${ }^{13-18}$ The prognostic value of NLR between early-stage and advanced-stage oral cancer is different. An NLR > 1.9 in advanced oral cancer showed reduced $\mathrm{DSS}^{15}$ in our data, but 2.95 was much higher in the prognostic value of early-stage tongue cancer. In addition, the relationship between NLR and subsites of HNSCC was not thoroughly evaluated. 

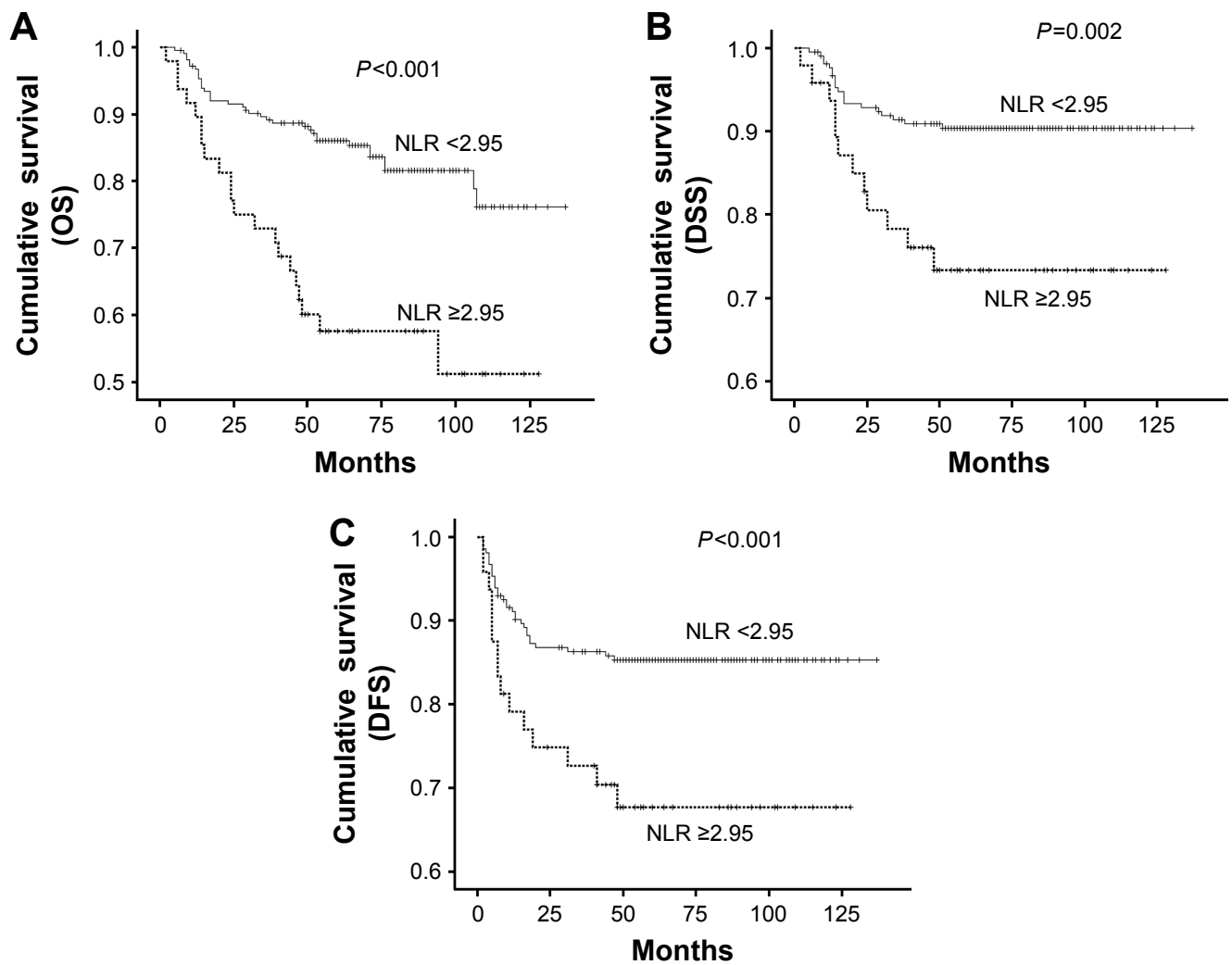

Figure 2 Kaplan-Meier analysis of patients with early-stage tongue cancer, by NLR with cutting in 2.95 .

Note: (A) Overall survival, (B) disease-specific survival, and (C) disease-free survival.

Abbreviations: OS, overall survival; DSS, disease-specific survival; DFS, disease-free survival; NLR, neutrophil-to-lymphocyte ratio.
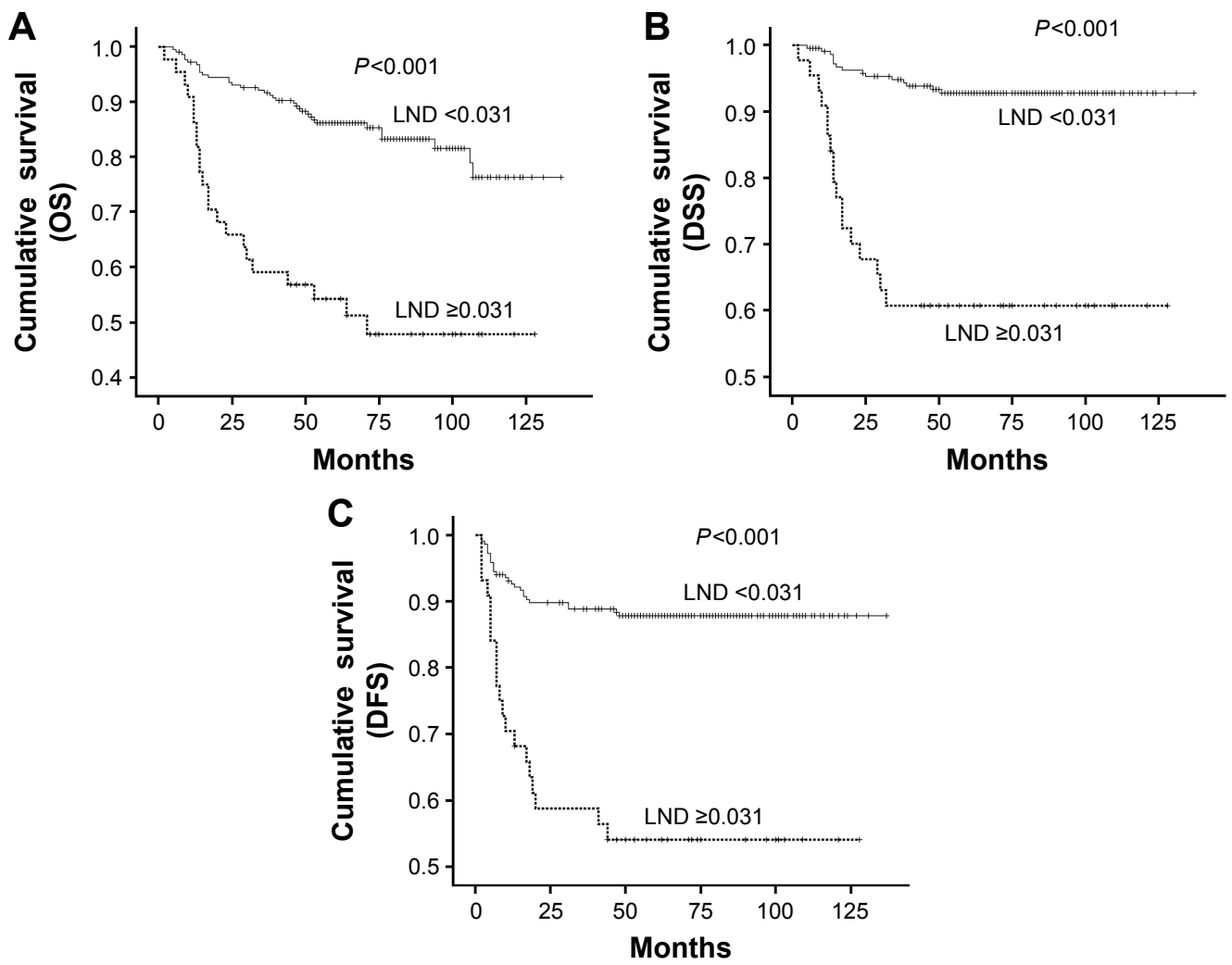

Figure 3 Kaplan-Meier analysis of patients with early-stage tongue cancer, by LND with cutting in $0.03 \mathrm{I}$.

Note: (A) Overall survival, (B) disease-specific survival, and (C) disease-free survival.

Abbreviations: OS, overall survival; DSS, disease-specific survival; DFS, disease-free survival; LND, lymph node density. 
Table 3 Univariate survival analysis of prognostic factors

\begin{tabular}{|c|c|c|c|}
\hline Factor & 5-year OS & 5-year DSS & 5-year DFS \\
\hline NLR & $P<0.001$ & $P=0.002$ & $P=0.004$ \\
\hline$<2.95$ & $86.0 \%$ & $90.4 \%$ & $85.3 \%$ \\
\hline$\geq 2.95$ & $57.6 \%$ & $73.3 \%$ & $67.7 \%$ \\
\hline LND & $P<0.00$ I & $P<0.001$ & $P<0.00$ I \\
\hline$<0.031$ & $86.2 \%$ & $92.8 \%$ & $87.8 \%$ \\
\hline$\geq 0.031$ & $54.2 \%$ & $60.7 \%$ & $54.1 \%$ \\
\hline T classification & $P<0.001$ & $P<0.001$ & $P<0.001$ \\
\hline $\mathrm{TI}$ & $88.2 \%$ & $94.5 \%$ & $90.5 \%$ \\
\hline $\mathrm{T} 2$ & $70.9 \%$ & $77.7 \%$ & $71.0 \%$ \\
\hline $\mathrm{N}$ classification & $P<0.00$ & $P<0.001$ & $P<0.00$ \\
\hline No & $85.3 \%$ & $92.3 \%$ & $87.1 \%$ \\
\hline $\mathrm{N}+$ & $64.6 \%$ & $69.8 \%$ & $64.6 \%$ \\
\hline Tumor thickness & $P<0.00$ & $P<0.001$ & $P<0.00$ \\
\hline$<5 \mathrm{~mm}$ & $94.8 \%$ & $100.0 \%$ & $97.0 \%$ \\
\hline$\geq 5 \mathrm{~mm}$ & $72.0 \%$ & $79.3 \%$ & $72.8 \%$ \\
\hline PNI & $P=0.00 \mathrm{I}$ & $P<0.001$ & $P<0.001$ \\
\hline No & $84.0 \%$ & $91.8 \%$ & $87.2 \%$ \\
\hline Yes & $65.9 \%$ & $67.4 \%$ & $59.5 \%$ \\
\hline LVI & $P=0.074$ & $P=0.043$ & $P=0.065$ \\
\hline No & $88.4 \%$ & $88.9 \%$ & $83.8 \%$ \\
\hline Yes & $67.1 \%$ & $74.7 \%$ & $68.8 \%$ \\
\hline ENE & $P<0.001$ & $P<0.001$ & $P<0.00$ \\
\hline No & $82.7 \%$ & $89.8 \%$ & $85.0 \%$ \\
\hline Yes & $52.9 \%$ & $52.9 \%$ & $41.2 \%$ \\
\hline Drinks alcohol & $P=0.078$ & $P=0.383$ & $P=0.15$ \\
\hline No & $82.9 \%$ & $88.6 \%$ & $84.3 \%$ \\
\hline Yes & $76.0 \%$ & $84.7 \%$ & $77.2 \%$ \\
\hline Betel nut chewing & $P=0.003$ & $P=0.055$ & $P=0.009$ \\
\hline No & $92.8 \%$ & $94.1 \%$ & $92.7 \%$ \\
\hline Yes & $76.5 \%$ & $84.9 \%$ & $78.3 \%$ \\
\hline Smoker & $P=0.016$ & $P=0.035$ & $P=0.10$ \\
\hline No & $92.2 \%$ & $95.1 \%$ & $89.0 \%$ \\
\hline Yes & $77.1 \%$ & $84.8 \%$ & $79.9 \%$ \\
\hline
\end{tabular}

Abbreviations: DFS, disease-free survival; DSS, disease-specific survival; ENE, extranodal extension; LND, lymph node density; LVI, lymphovascular invasion; NLR, neutrophil-to-lymphocyte ratio; OS, overall survival; PNI, perineural invasion.

Our result is comparable to these findings, showing that a high NLR is a poor prognostic factor in early-stage (cT1/T2N0) tongue cancer, although the cutoff value is different from that in previous studies. In our study, patients

Table 4 Multivariate analysis of prognostic factors for 5-year overall survival

\begin{tabular}{llll}
\hline Factor & Hazard ratio & $\mathbf{9 5 \%} \mathbf{C l}$ & P-value \\
\hline NLR & & & 0.003 \\
$\quad<2.95$ & $\mathrm{I}$ & $(1.326-3.962)$ & \\
$\quad \geq 2.95$ & 2.292 & & 0.001 \\
LND & & & \\
$\quad<0.031$ & $\mathrm{I}$ & $(\mathrm{I} .476-4.487)$ & \\
$\quad \geq 0.03 \mathrm{I}$ & 2.573 & & 0.004 \\
$\begin{array}{l}\text { Tumor thickness } \\
\quad<5 \mathrm{~mm}\end{array}$ & $\mathrm{I}$ & & \\
$\geq 5 \mathrm{~mm}$ & 3.383 & $(\mathrm{I} .482-7.722)$ & \\
\hline
\end{tabular}

Abbreviations: LND, lymph node density; NLR, neutrophil-to-lymphocyte ratio.
Table 5 Multivariate analysis of prognostic factors for 5-year disease-specific survival

\begin{tabular}{llll}
\hline Factor & Hazard ratio & $\mathbf{9 5 \%} \mathbf{C l}$ & $P$-value \\
\hline $\begin{array}{l}\text { NLR } \\
<2.95\end{array}$ & $\mathrm{I}$ & & 0.048 \\
$\geq 2.95$ & 2.106 & $(\mathrm{I} .007-4.405)$ & \\
$\mathrm{LND}$ & & & $<0.00 \mathrm{I}$ \\
$\quad<0.03 \mathrm{I}$ & $\mathrm{I}$ & $(2.55 \mathrm{I}-10.427)$ & \\
$\geq 0.03 \mathrm{I}$ & 5.157 & & 0.006 \\
T classification & & & \\
TI & $\mathrm{I}$ & $(\mathrm{I} .39-7.352)$ & \\
$\quad$ T2 & 3.196 & & 0.036 \\
LVI & & & \\
No & $\mathrm{I}$ & $(\mathrm{I} .06-5.892)$ & \\
Yes & 2.499 &
\end{tabular}

Abbreviations: LND, lymph node density; LVI, lymphovascular invasion; NLR, neutrophil-to-lymphocyte ratio.

with NLR $>2.95$ have significantly reduced OS, DSS, and DFS that still remained significant on multivariate analysis (Tables 4-6). Interestingly, in our study, patients with NLR $\geq 2.95$ correlated significantly with positive N classification, T2 classification, positive PNI, and a tumor thickness of $>5 \mathrm{~mm}$. This means that patients with NLR $\geq 2.95$ in early-stage (cT1/T2N0) tongue cancer show more aggressive tumor behavior, leading to dismal prognosis. This is a novel finding about the relationship between NLR and the pathological adverse features in oral cancer.

The possible mechanism of tumor aggressiveness may come from the inflammation itself, which contributes to cancer initiation and progression. The inflammatory microenvironment would induce genotoxic stress via multiple mechanisms, including reactive oxygen species and induction of activation-induced cytidine deaminase. ${ }^{36}$ Inflammation's role in the development of lung cancer

Table 6 Multivariate analysis of prognostic factors for 5-year disease-free survival

\begin{tabular}{llll}
\hline Factor & Hazard ratio & $\mathbf{9 5 \%} \mathbf{C l}$ & P-value \\
\hline $\begin{array}{l}\text { NLR } \\
\quad<3.0\end{array}$ & $\mathrm{I}$ & & 0.043 \\
$\quad \geq 3.0$ & $\mathrm{I} .914$ & $(1.02-3.595)$ & \\
LND & & & 0.070 \\
$\quad<0.03 \mathrm{I}$ & $\mathrm{I}$ & & \\
$\quad \geq 0.03 \mathrm{I}$ & $\mathrm{I} .987$ & $(0.946-4.17 \mathrm{I})$ & \\
$\begin{array}{l}\text { Tumor thickness } \\
\quad<5 \mathrm{~mm}\end{array}$ & $\mathrm{I}$ & & 0.002 \\
$\quad \geq 5 \mathrm{~mm}$ & 6.909 & $(2.083-22.917)$ & \\
ENE & & & 0.057 \\
$\quad$ No & $\mathrm{I}$ & & \\
$\quad$ Yes & $2.37 \mathrm{I}$ & $(0.976-5.759)$ & \\
\hline
\end{tabular}

Abbreviations: ENE, extranodal extension; LND, lymph node density; NLR, neutrophil-to-lymphocyte ratio. 
Table 7 Different studies about the lymph node density in head and neck cancer

\begin{tabular}{|c|c|c|c|c|c|c|}
\hline Reference & Site & Case number & Cutoff for LND & 5-year OS & 5-year DSS & 5-year DFS \\
\hline Gil et $a^{28}$ & Oral cancer & 386 & 0.06 & $58 \%$ vs $28 \%$ & $65 \%$ vs $34 \%$ & - \\
\hline Shrime et $\mathrm{al}^{29}$ & Oral cancer & 143 & 0.13 & $44.7 \%$ vs $16.1 \%$ & - & - \\
\hline Kim et $\mathrm{al}^{30}$ & Oral cancer & 78 & 0.06 & $75 \%$ vs $38 \%$ & $80 \%$ vs $47 \%$ & - \\
\hline Amar et $\mathrm{a}^{3 !}$ & Oral cancer & 182 & 0.06 & - & - & $44 \%$ vs $28 \%$ \\
\hline Liao et $\mathrm{al}^{32}$ & Oral cancer & 148 & 0.048 & $66 \%$ vs $21 \%$ & $78 \%$ vs $28 \%$ & $75 \%$ vs $24 \%$ \\
\hline Patel et $\mathrm{a}^{33}$ & Oral cancer & 4,254 & 0.07 & $49 \%$ vs $35 \%$ & $60 \%$ vs $41 \%$ & - \\
\hline Rudra et al ${ }^{34}$ & HNSCC & 38 & 0.2 & $79 \%$ vs $50 \%$ & - & $89 \%$ vs $68 \%$ \\
\hline Ong et $\mathrm{a}^{35}$ & Tongue cancer & 99 & 0.06 & $58 \%$ vs $47 \%$ & $58 \%$ vs $48 \%$ & - \\
\hline Our current study & Early tongue cancer & 262 & 0.031 & $86 \%$ vs $54 \%$ & $93 \%$ vs $61 \%$ & $88 \%$ vs $54 \%$ \\
\hline
\end{tabular}

Abbreviations: DFS, disease-free survival; DSS, disease-specific survival; HNSCC, head and neck squamous cell carcinoma; LND, lymph node density; OS, overall survival.

Table 8 Different studies about neutrophil-to-lymphocyte ratio in head and neck cancer

\begin{tabular}{lllll}
\hline Reference & Site & Case number & Cutoff for NLR & Outcome measurement \\
\hline He et al $^{13}$ & Nasopharyngeal carcinoma & 1,410 & 1.54 & OS and PFS \\
Fang et al ${ }^{14}$ & Oral cancer & 226 & 2.44 & OS and DFS \\
Perisanidis et al & Locally advanced oral cancer & 97 & 1.9 & DSS \\
Rassouli et al $^{17}$ & HNSCC & 273 & 4.27 & DSS \\
Salim et al & Recurrent/metastatic HNSCC & 79 & 2.93 & DSS \\
Haddad et al ${ }^{16}$ & Locally advanced HNSCC & 46 & 5 & OS, MFS, LRRFS \\
Our current study & Early tongue cancer & 262 & 2.95 & OS, DSS, DFS \\
\hline
\end{tabular}

Abbreviations: DFS, disease-free survival; DSS, disease-specific survival; HNSCC, head and neck squamous cell carcinoma; LRRFS, local/regional relapse-free survival; MFS, metastatic-free survival; NLR, neutrophil-to-lymphocyte ratio; OS, overall survival; PFS, progression free survival.

from smoking is clear. In mice, smoking causes chronic inflammation by activating the nuclear factor-kappa B and mitogen-activated protein kinase pathways, consequently contributing to the formation of lung cancer. ${ }^{37}$ Another example, circulating CD105, is recognized as a specific marker in ongoing angiogenesis related to tumor growth, and its expression was found to be elevated in inflammatory tissue. In our previous study, we proved that higher circulating CD105 promotes malignancy of cancer cells in oral cancer. ${ }^{38}$ Importantly, in cancer patients, the neutrophil and/or lymphocyte counts forming NLR could be influenced by comorbid diseases, such as chronic inflammatory and autoimmune diseases, and by the intake of medications for immunodeficiency diseases, such as glucocorticosteroids and anti-inflammatory drugs. It is necessary to take notice of the above conditions before using NLR clinically.

\section{Conclusion}

Patients with early-stage (cT1/T2N0) tongue cancer and with NLR $\geq 2.95$ show greater chance of aggressive clinicopathological adverse features, such as larger tumors, perineural invasion, and positive neck metastasis, leading to a reduced survival rate. If the NLR $\geq 2.95$ in early-stage (cT1/T2N0) tongue cancer is noted, it should be treated as a very invasive tumor, and treatment should include elective neck dissection.

\section{Acknowledgments}

This study was supported by grant numbers CMRPG8A0961, CMRPG8D1421-2, CMRPG8C0071, CMRPG8B0971-2, CMRPG8C0071, and CMRP100-0689B from the Chang Gung Memorial Hospital.

We must express our gratitude to Drs Tai-Lin Huang, Tai-Jan Chiu, and Hui Lu for their effort and advice in the preparation of this manuscript.

\section{Disclosure}

The authors report no conflicts of interest in this work.

\section{References}

1. Asakage T, Yokose T, Mukai K, et al. Tumor thickness predicts cervical metastasis in patients with stage I/II carcinoma of the tongue. Cancer. 1998;82(8): 1443-1448.

2. Chuang HC, Su CY, Huang HY, Chien CY, Chen CM, Huang CC. High expression of CD105 as a prognostic predictor of early tongue cancer. Laryngoscope. 2006;116(7):1175-1179.

3. Chien CY, Su CY, Chuang HC, et al. The clinical significance of osteopontin expression in T1 and T2 tongue cancers. Head Neck. 2008; 30(6):776-781.

4. Kim RY, Ward BB, Brockhoff HC, et al. Correlation of lymph node density with negative outcome predictors in oral and xaxillofacial squamous cell carcinoma. J Oral Maxillofac Surg. 2016;74:2081-2084.

5. Mantovani A, Allavena P, Sica A, Balkwill F. Cancer-related inflammation. Nature. 2008;454(7203):436-444.

6. Grivennikov SI, Greten FR, Karin M. Immunity, inflammation, and cancer. Cell. 2010;140(6):883-899.

7. Sharaiha RZ, Halazun KJ, Mirza F, et al. Elevated preoperative neutrophil: lymphocyte ratio as a predictor of postoperative disease recurrence in esophageal cancer. Ann Surg Oncol. 2011;18(12):3362-3369. 
8. Feng JF, Huang Y, Liu JS. Combination of neutrophil to lymphocyte ratio and platelet lymphocyte ratio a useful predictor of postoperative survival in patients with esophageal squamous cell carcinoma. Onco Targets Ther. 2013;6:1605-1612.

9. Teramukai S, Kitano T, Kishida Y, et al. Pretreatment neutrophil count as an independent prognostic factor in advanced non-small-cell lung cancer: an analysis of Japan multinational trial organisation LC00-03. Eur J Cancer. 2009;45(11):1950-1958.

10. Halazun KJ, Hardy MA, Rana AA, et al. Negative impact of neutrophillymphocyte ratio on outcome after liver transplantation for hepatocellular carcinoma. Ann Surg. 2009;250(1):141-151.

11. Wang DS, Luo HY, Qiu MZ, et al. Comparison of the prognostic values of various inflammation based factors in patients with pancreatic cancer. Med Oncol. 2012;29(5):3092-3100.

12. Pan QX, Su ZJ, Zhang JH, Wang CR, Ke SY. A comparison of the prognostic value of preoperative inflammation-based scores and TNM stage in patients with gastric cancer. Onco Targets Ther. 2015; 8:1375-1385.

13. He JR, Shen GP, Ren ZF, et al. Pretreatment levels of peripheral neutrophils and lymphocytes as independent prognostic factors in patients with nasopharyngeal carcinoma. Head Neck. 2012;34(12):1769-1776.

14. Fang HY, Huang XY, Chien HT, et al. Refining the role of preoperative C-reactive protein by neutrophil/lymphocyte ratio in oral cavity squamous cell carcinoma. Laryngoscope. 2013;123(11): 2690-2699.

15. Perisanidis C, Kornek G, Poschl PW, et al. High neutrophil-tolymphocyte ratio is an independent marker of poor disease-specific survival in patients with oral cancer. Med Oncol. 2013;30(1):334.

16. Haddad CR, Guo L, Clarke S, Guminski A, Back M, Eade T. Neutrophilto-lymphocyte ratio in head and neck cancer. $J$ Med Imaging Radiat Oncol. 2015;59(4):514-519.

17. Rassouli A, Saliba J, Castano R, Hier M, Zeitouni AG. Systemic inflammatory markers as independent prognosticators of head and neck squamous cell carcinoma. Head Neck. 2015;37(1):103-110.

18. Salim DK, Mutlu H, Eryilmaz MK, et al. Neutrophil to lymphocyte ratio is an independent prognostic factor in patients with recurrent or metastatic head and neck squamous cell cancer. Mol Clin Oncol. 2015;3(4): 839-842.

19. Abu-Ghanem S, Yehuda M, Carmel NN, et al. Elective neck dissection vs observation in early-stage squamous cell carcinoma of the oral tongue with no clinically apparent lymph node metastasis in the neck: a systematic review and meta-analysis. JAMA Otolaryngol Head Neck Surg. 2016;142:857-865

20. Pentenero M, Gandolfo S, Carrozzo M. Importance of tumor thickness and depth of invasion in nodal involvement and prognosis of oral squamous cell carcinoma: a review of the literature. Head Neck. 2005; 27(12):1080-1091.

21. Chuang HC, Fang FM, Huang CC, et al. Clinical and pathological determinants in tonsillar cancer. Head Neck. 2011;33(12):1703-1707.

22. Preda L, Chiesa F, Calabrese L, et al. Relationship between histologic thickness of tongue carcinoma and thickness estimated from preoperative MRI. Eur Radiol. 2006;16(10):2242-2248.

23. Yuen AP, Ng RW, Lam PK, Ho A. Preoperative measurement of tumor thickness of oral tongue carcinoma with intraoral ultrasonography. Head Neck. 2008;30(2):230-234.
24. Lin YT, Chien CY, Lu CT, et al. Triple-positive pathological findings in oral cavity cancer are related to a dismal prognosis. Laryngoscope. 2015;125(9):E300-E305.

25. Al-Swiahb JN, Chen CH, Chuang HC, Fang FM, Chien CY. Clinical, pathological, and molecular determinants in squamous cell carcinoma of the oral cavity. Future Oncol. 2010;6(5):837-850.

26. Ebrahimi A, Gil Z, Amit M, et al; International Consortium for Outcome Research (ICOR) in Head and Neck Cancer. A Comparison of the American Joint Committee on Cancer N1 versus N2a nodal categories for predicting survival and recurrence in patients with oral cancer: time to acknowledge an arbitrary distinction and modify the system. Head Neck. 2016;38(1):135-139.

27. Kassouf W, Agarwal PK, Herr HW, et al. Lymph node density is superior to TNM nodal status in predicting disease-specific survival after radical cystectomy for bladder cancer: analysis of pooled data from MDACC and MSKCC. J Clin Oncol. 2008;26(1):121-126.

28. Gil Z, Carlson DL, Boyle JO, et al. Lymph node density is a significant predictor of outcome in patients with oral cancer. Cancer. 2009; 115(24):5700-5710.

29. Shrime MG, Bachar G, Lea J, et al. Nodal ratio as an independent predictor of survival in squamous cell carcinoma of the oral cavity. Head Neck. 2009;31(11):1482-1488.

30. Kim SY, Nam SY, Choi SH, Cho KJ, Roh JL. Prognostic value of lymph node density in node-positive patients with oral squamous cell carcinoma. Ann Surg Oncol. 2011;18(8):2310-2317.

31. Amar A, Rapoport A, Curioni OA, Dedivitis RA, Cernea CR, Brandao LG. The density of metastatic lymph node as prognostic factor in squamous cell carcinoma of the tongue and floor of the mouth. Braz J Otorhinolaryngol. 2012;78(3):86-90. Portuguese.

32. Liao CT, Hsueh C, Lee LY, et al. Neck dissection field and lymph node density predict prognosis in patients with oral cavity cancer and pathological node metastases treated with adjuvant therapy. Oral Oncol. 2012;48(4):329-336.

33. Patel SG, Amit M, Yen TC, et al; International Consortium for Outcome Research (ICOR) in Head and Neck Cancer. Lymph node density in oral cavity cancer: results of the International Consortium for Outcomes Research. Br J Cancer. 2013;109(8):2087-2095.

34. Rudra S, Spiotto MT, Witt ME, Blair EA, Stenson K, Haraf DJ. Lymph node density-prognostic value in head and neck cancer. Head Neck. 2014;36(2):266-272.

35. Ong W, Zhao R, Lui B, et al. Prognostic significance of lymph node density in squamous cell carcinoma of the tongue. Head Neck. 2016; 38(Suppl 1):E859-E866.

36. Okazaki IM, Kotani A, Honjo T. Role of AID in tumorigenesis. $A d v$ Immunol. 2007;94:245-273.

37. Takahashi H, Ogata H, Nishigaki R, Broide DH, Karin M. Tobacco smoke promotes lung tumorigenesis by triggering IKKbeta- and JNK1dependent inflammation. Cancer Cell. 2010;17(1):89-97.

38. Chen $\mathrm{CH}$, Chuang HC, Lin YT, et al. Circulating CD105 shows significant impact in patients of oral cancer and promotes malignancy of cancer cells via CCL20. Tumour Biol. 2016;37(2):1995-2005.

39. World Health Organization; International Agency for Research on Cancer. GLOBOCAN 2012: Estimated cancer incidence, mortality and prevalence worldwide in 2012. Available from: http://globocan.iarc.fr/ Default.aspx. Accessed June 3, 2017.
OncoTargets and Therapy

\section{Publish your work in this journal}

OncoTargets and Therapy is an international, peer-reviewed, open access journal focusing on the pathological basis of all cancers, potential targets for therapy and treatment protocols employed to improve the management of cancer patients. The journal also focuses on the impact of management programs and new therapeutic agents and protocols on
Dovepress

patient perspectives such as quality of life, adherence and satisfaction. The manuscript management system is completely online and includes a very quick and fair peer-review system, which is all easy to use. Visit http://www.dovepress.com/testimonials.php to read real quotes from published authors. 